\title{
THE RELATIONSHIP BETWEEN STATIC AND DYNAMIC BALANCE IN ACTIVE YOUNG ADULTS
}

original paper

() Wroclaw University of Health and Sport Sciences

DOI: https://doi.org/10.5114/hm.2021.106165

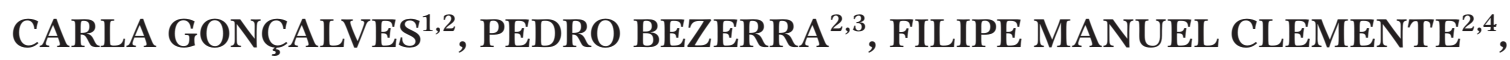
CAROLINA VILA-CHÃ $\tilde{A}^{3,5}$, CESAR LEÃO ${ }^{2}$, ANTÓNIO BRANDÃO $^{2}$, JOSE M. CANCELA ${ }^{1}$

\footnotetext{
${ }^{1}$ Faculty of Educational Sciences and Sports Sciences, University of Vigo, Vigo, Spain

${ }^{2}$ Escola Superior de Desporto e Lazer, Instituto Politécnico de Viana do Castelo, Melgaço, Portugal

${ }^{3}$ Research Centre in Sports Sciences, Health Sciences and Human Development, Vila Real, Portugal

${ }^{4}$ Instituto de Telecomunicações, Delegação da Covilhã, Covilhã, Portugal

${ }^{5}$ Instituto Politécnico da Guarda, Guarda, Portugal
}

\section{ABSTRACT}

Purpose. The objectives were to analyse differences of static and dynamic balance between sexes and test the correlations between static and dynamic balance measures.

Methods. The study involved 77 physically active adults, university students (age: $19.1 \pm 1.1$ years; height: $170.2 \pm 9.2 \mathrm{~cm}$; body mass: $64.1 \pm 10.7 \mathrm{~kg}$ ). Static balance was assessed with a force platform under Romberg conditions: a foam surface, eyes open (EOFS); eyes closed (ECFS); challenging the visual-vestibular system (CVVS). The Y Balance Test (YBT) evaluated dynamic balance in anterior, posteromedial, and posterolateral directions. One-way ANOVA examined potential differences between sexes, and the Pearson product-moment test verified the correlations between YBT and static balance measures. Results. Sex differences were found for all conditions in static balance variables: ellipse area (EA), centre of pressure displacement anteroposterior (DAP) and mediolateral (DML), mean velocity anteroposterior (VAP) and mediolateral (VML), total mean velocity (TV). Females presented a better stability index than males for EOFS (25\% DAP, 20\% DML, 30\% VAP, 21\% VML, 19\% TV), ECFS (26\% DAP, 32\% DML, 28\% VAP, 32\% VML, 32\% TV), and CVVS (27\% EA, 26\% DAP, 19\% DML, 17\% VAP, 20\% VML, 18\% TV). Males demonstrated 6\% better performance on YBT posterolateral. Correlation tests revealed small to moderate correlations between static and dynamic balance, except for a large positive correlation between YBT anterior and sway area under the CVVS condition $[r=0.54(0.19 ; 0.77)]$ for women.

Conclusions. The findings indicate a weak relationship between static and dynamic balance in controlling posture.

Key words: static balance, force plate, young adults, dynamic balance, Y Balance Test, university students

\section{Introduction}

Postural control is a complex motor function based on interactions between multiple dynamic sensorimotor processes whose main functional goals are body stability, postural orientation, and balance [1]. Postural balance is the ability to control one's position while maintaining the centre of gravity within the limits of stability over a base of support. Movement strategies and muscular synergies must be coordinated to stabilize the centre of body mass and minimize the displacements of the centre of pressure (COP) while assuming a quasi-static position or performing daily movements or exercise [1, 2]. Postural balance is considered as the state in which all forces acting on the human body (gravity, muscle strength, and inertial forces) are controlled and the body adopts a desired position, achieves quasi-static balance, or performs a specific movement without losing balance [1-4].

Previous literature related to postural balance is grouped into static and dynamic categories [1, 2]. Static postural stability can be defined as the maintenance of a steady position on a fixed, firm, stable support base. Dynamic postural stability is the ability to transfer the vertical projection of one's centre of gravity around the supporting base using a perturbation on the sup-

Correspondence address: Carla Gonçalves, Complexo Desportivo e de Lazer Comendador Rui Solheiro Monte de Prado, 4960-320 Melgaço, Portugal, e-mail: carlagoncalves@esdl.ipvc.pt

Received: September 10, 2020

Accepted for publication: December 7, 2020

Citation: Gonçalves C, Bezerra P, Clemente FM, Vila-Chã C, Leão C, Brandão A, Cancela JM. The relationship between static and dynamic balance in active young adults. Hum Mov. 2022;23(2):65-75; doi: https://doi.org/10.5114/hm.2021.106165. 


\section{HUMAN MOVEMENT}

C. Gonçalves et al., Relationship between static and dynamic balance

port surface or the individual. Dynamic postural stability can also refer to an individual's ability to maintain their balance after a change in position or location $[1,2,4]$. The central nervous system needs to keep the body position under static and dynamic conditions to maintain balance and produce suitable forces. Proper balance control constitutes the basis for the execution of complex technical movements and improvements in athletic performance [5]. In fact, measuring postural stability and static and dynamic balance is critical to determine predictors of sports performance [6], rehabilitation, injury prevention [7], as well as to assess the efficacy of balance training in the neuromuscular system, balance control, and functional performance among children, adolescents [8], and active young adults [9-11]. Therefore, balance control has attracted the interest of professionals from different fields.

When the goal of a study is to assess static or dynamic posture, the most common posturographic measure used is the COP sway [4]. COP expresses the point of application of the resultant from the vertical force action on the support surface [4]. The literature has cited the importance of analysing COP oscillations while standing on a force plate, as such COP oscillations represent a complex output signal of postural control and the inherent complexity of cognitive, perceptual, and motor processes [4] while challenging the sensory system by altering vision, stance, or surface conditions $[4,12]$. The equipment most often used to evaluate $\mathrm{COP}$ is a force plate $[4,13-15]$. The parameters collected from force plate output (i.e., COP path length, COP excursion, speed of COP change, mean amplitude of COP sway) can represent stability when in a quiet standing position or when maintaining a stable position while carrying out a prescribed movement [4]. However, beyond posturography based on force plate assessments, previous researchers have utilized different instruments to assess dynamic balance. Such instruments include the Balance Error Scoring System [16], the jumping test [17], the Star Excursion Balance Test (SEBT) [18], and the Y Balance Test (YBT) [19, 20]. In fact, dynamic postural control involves various dimensions that also represent the performance of proprioception, the range of motion of lower limb joints, and muscle strength. Researchers have shown that YBT is an effective and objective method for assessing dynamic balance [20-22]. This instrument significantly challenges the postural control system through the completion of a functional task while maintaining a single-leg stance and reaching towards the anterior, posteromedial, or posterolateral direction with the free limb without losing balance [23]. YBT imposes additional demands related to proprioception, range of motion, and strength while the participant remains in a steady, upright position [23].

Although several studies have assessed postural balance in young adults [24, 25], it has not been thoroughly investigated whether static balance reflects dynamic balance. It also remains unclear if sex differences influence this analysis. Hrysomallis et al. [26] were the first to determine the association between static and dynamic balance. Their results indicate a low correlation between the balance scores for the static test (single-limb stance) and the stepping test on an unstable surface. Karimi and Solomonidis [27] instructed the participants to stand on a force plate in a quiet standing position while undertaking various tasks involving their hands. They observed no significant correlation between static and dynamic stability parameters [27]. Sell [28] assessed static postural stability while the participants assumed a single-leg stance (eyes open and eyes closed) and dynamic stability by using the anteroposterior and mediolateral jump. No correlation was found between static and dynamic postural measures.

All the researchers mentioned above studied the relationship between static and dynamic balance, and they all stated that there was no relationship between static and dynamic measures. However, their works varied in terms of methodology - specifically, each study involved different participants and balance tests [26-29]. Most of them implemented a static balance test with a stable surface, though unstable surfaces seem to make the static balance test more challenging and closer to sports contexts for young adults [15, 30]. Additionally, previous research used only one condition to assess static balance test performance; however, it is crucial to evaluate participants' balance when different systems (i.e., visual, proprioceptive [31], and vestibular) are challenged.

There are many balance assessment methods, ranging from simple observations, clinical tests, scales, and posturographic measurements, to integrated evaluation systems of greater complexity. Each method has advantages and limitations and can demonstrate different results with multiple interpretations; this is exacerbated by the lack of consensus regarding which characteristics (e.g., gender) are important [31, 32]. Few studies have examined gender differences in terms of postural stability among young adults as measured by static balance (COP displacement and velocity) and 
dynamic balance (maximal lower limb reach scores). Additional literature does not seem congruent. Some studies show that women have a better stability index than men [31-33], while others report contradictory results [34,35]. The relationship between static and dynamic balance control considering sex differences has not been researched. Thus, it is important to know whether males differ from females in terms of balance control and to understand the relationship between gender and balance control measures [31, 32]. A better understanding of the influence of sex on balance control is central to establishing reference data that would allow the detection of balance disorders. Such an understanding might also assist physical activity and health professionals and coaches in prescribing balance training programs.

In short, there is a lack of evidence regarding the relationship between static (force plate with an unstable surface) and dynamic balance (anterior, posteromedial, and posterolateral lower limb reach). An understanding of whether sex influences COP parameters and YBT measures is also lacking. Thus, the purpose of this study was twofold: (i) to analyse the variations in static and dynamic balance between the sexes and (ii) to establish the relationships between static and dynamic balance measures.

\section{Material and methods}

\section{Experimental approach to the problem}

A cross-sectional design was used to analyse the relationship between static and dynamic balance control measures. The sample consisted of physically active young adults, university students, taking leisure sports courses ( $1^{\text {st }}$ and $2^{\text {nd }}$ year) who participated in training at least 3 days per week. The participants' anthropometric measures (height, body weight, and 8 -site skinfolds) were assessed in a laboratory at a constant environmental temperature and humidity (20$23^{\circ} \mathrm{C}$ and $50-60 \%$, respectively) before breakfast on a weekday (48 hours after the last training/exercise session) between 8:30 a.m. and 10:00 a.m. All participants wore light clothing and stood barefoot. They were instructed to avoid exercise for a minimum of 24 hours before testing and not to consume alcoholic drinks for a minimum of 48 hours before testing. Static balance control was recorded by using a force plate (Kistler, model 9260AA6, Winterthur, Switzerland). The subjects completed three 30 -second trials on a foam surface under 3 different conditions: eyes open (EOFS), eyes closed (ECFS), and challenging the visual-vestibular system (CVVS). The trial order was randomized across the participants to reduce order effects [36].

Before the testing began, each individual performed one practice trial for each condition. Dynamic postural control was assessed by using YBT (anterior, posteromedial, and posterolateral reach directions). Each participant performed 4 experimental practice trials for each direction to become comfortable with performing the task [37]. After 2 minutes of rest, each subject performed 3 test trials in each direction (accounted tests) [20]. The trial order (i.e., anterior, posteromedial, and posterolateral reach directions) was randomized across the participants to reduce order effects [36]. The results of both tests were recorded by an expert with experience in using the necessary equipment; the order of static and dynamic tests was randomized.

\section{Participants and design}

A total of 77 physically active young adults voluntarily participated in this study. Their anthropometric characteristics can be found in Table 1. The subjects completed a medical history questionnaire and the International Physical Activity Questionnaire (IPAQ-short form) so that physical activity could be measured. The inclusion criteria in the study were (1) training at least 3 days per week and (2) absence of acute injuries. The exclusion criteria involved (1) previous experience with functional training with unstable platforms or sports that develop balance and proprioceptive skills (e.g., dance, ballet, hockey) and (2) neuromuscular diseases, vestibular disorders, cerebral concussions, chronic lower limb injuries or any pathology or health problem that affects balance and postural control [15, 38].

\section{Anthropometric measures}

Each participant's height was measured to the nearest $0.1 \mathrm{~cm}$ with a portable stadiometer (Seca 217, Hamburg, Germany). Body weight was determined to the nearest $0.1 \mathrm{~kg}$ with mechanical floor scales (Seca 760, Germany). Eight skinfolds were assessed with a Harpenden calliper (British Indicators, Ltd., London, UK) to estimate body fat percentage. All anthropometric variables were measured in accordance with the International Society for the Advancement of Kinanthropometry (ISAK) protocol by a single certified expert 


\section{HUMAN MOVEMENT}

C. Gonçalves et al., Relationship between static and dynamic balance

(ISAK Level 2). A test-retest analysis was made to the observer aiming to ensure an appropriate level of reliability. Using 10\% of the full data, 3 trials were tested and the reliability level of intraclass correlation tested revealed a value of intraclass correlation coefficient of 0.96, i.e. an excellent reliability level.

\section{Lower limb length}

The leg that kicked the ball was considered the dominant leg. Limb length (from the anterior superior iliac spine to the most distal portion of the medial malleolus) was measured in centimetres for 3 trials with a tape measure. The average of the 3 trials was recorded. Leg length was used to normalize YBT excursion distances by dividing the average of 3 maximal reaches by leg length and multiplying the result by 100 [23, 39].

\section{Postural control measures}

Static postural control was recorded by using a force plate under 3 different conditions on a foam surface; dynamic postural control was assessed by YBT with anterior, posteromedial, and posterolateral reach directions.

\section{Static postural control}

Static postural control under unstable conditions was assessed by measuring COP fluctuations at $1000 \mathrm{~Hz}$ with a force plate (Kistler, model 9260AA6). The participants stood barefoot on a foam surface (density: $50 \mathrm{~kg} / \mathrm{m}^{3}$; dimensions: $49 \times 39 \times 5.5 \mathrm{~cm}$ ) placed on top of a force plate. They completed three 30-second trials under 3 different conditions: (a) quiet standing, eyes open (EOFS); (b) quiet standing, eyes closed (ECFS); and (c) quiet standing, eyes open, challenging the visual-vestibular system (CVVS) (looking at light signals that changed 10 to 10 seconds: $1^{\circ}$ eye level, $1.80 \mathrm{~m}$ off the ground; $2^{\circ}$ looking up, $3.60 \mathrm{~m}$ off the ground; $3^{\circ}$ looking to the ground; $4^{\circ}$ eye level). The participants were given 1 minute of rest between the trials [36] and 1 minute of rest between the conditions [15]. The trial order (i.e., EOFS, ECFS, CVVS) was randomized across the subjects to reduce order effects [36]. Each individual could select their preferred stance width [4] and was instructed to stand quietly with their arms hanging at the sides while they placed their head in a normal forward-looking position and focused on a target located at the eye level, approximately $3 \mathrm{~m}$ away [15]. Before testing, each participant performed one exper- imental practice trial for each condition, and then data for 3 trials were collected for each condition. The average of the 3 trials was used for further analysis.

The force and torque signals were amplified (data acquisition system type 5695B, Winterthur, Switzerland) and recorded with commercial software (BioWare, 2812A), which computed the COP time series in the anteroposterior and mediolateral directions. After filtering (fourth-order zero-lag $20 \mathrm{~Hz}$ low-pass Butterworth filter), classical sway measures were computed to assess the direction, distance, and velocity of the COP trajectory, with greater values indicating poorer balance. These measures included: sway area, defined as the ellipse area that fits $95 \%$ of the COP data points $\left(\mathrm{cm}^{2}\right)$; total COP displacement, which represents the overall anteroposterior and mediolateral movement over 30 seconds (cm); and total mean velocity, which signifies the total COP distance travelled in one trial divided by the duration of the trial. Displacement and mean velocity in the anteroposterior and mediolateral directions were also computed. The length versus surface area parameter indicates the ratio of statokinesigram plot length to its area and assesses the energy expended by the subject during the examination [40]. All sway measures were computed through scripts written in the MATLAB code (R2013a, MathWorks Inc., Natick, MA, USA).

\section{Dynamic postural control}

Each participant completed YBT for the anterior, posteromedial, and posterolateral directions (Figure 1), modelled in accordance with the methodology described by Plisky et al. [39].

Demonstrations and verbal instruction were given to the subjects to inform them how the test should be performed. YBT was evaluated with a commercially available device (Octo Balance premium version system, Check your MOtion, SKU 1008, Spain). While the participants maintained a single-leg stance, the free limb moved to reach the anterior, posteromedial, and posterolateral directions (maximum possible reach) in relation to the stance foot. The participant then returned to a starting position without losing their balance [10, 39].

Each individual performed 4 experimental practice trials (unaccounted tests) for each direction so that they became comfortable performing the task. After 2 minutes of rest, each participant performed 3 test trials in each direction (accounted tests) [10]. The average of 3 maximal reaches was calculated and recorded. A 10-second rest was provided between the 


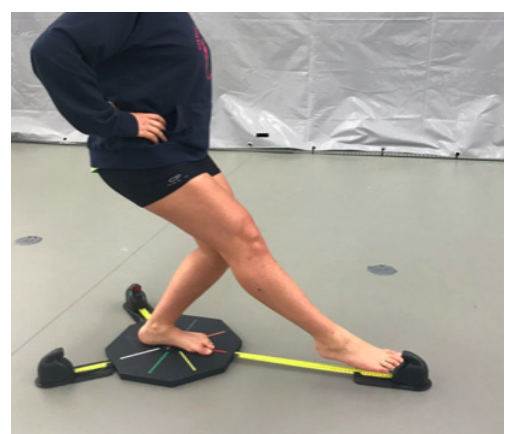

1

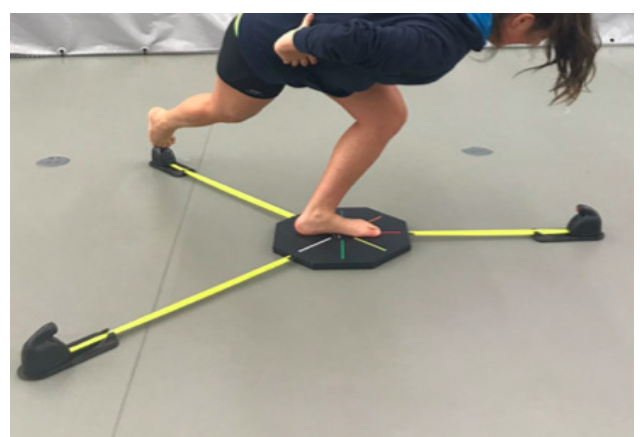

2

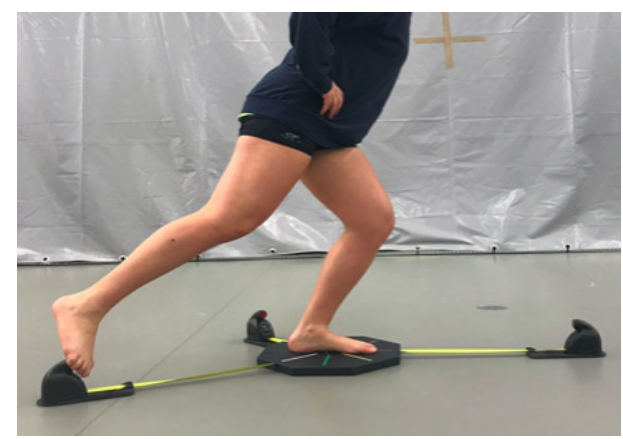

3

Figure 1. Y Balance Test: (1) anterior reach direction; (2) posterolateral reach direction; (3) posteromedial reach direction

reach trials [7]. A trial was classified as invalid if the participant removed their hands from their hips, did not return to the starting position, or failed to maintain a unilateral stance on the platform (e.g., if they placed the reach foot on the ground, raised or moved the stance foot during the test, or kicked the plate with the reach foot to gain distance) [7, 39, 41].

\section{Statistical procedures}

Descriptive statistics included mean, standard deviation, and 95\% confidence interval values. The normality of the sample was tested by using the Kolmogorov-Smirnov test. After confirming the assumption of normality, one-way ANOVA was executed to test the differences between the sexes in static and dynamic balance tests for each condition (EOFS, ECFS, and CVVS). For each condition, the Pearson product-moment $(r)$ test was applied to assess the magnitudes of correlations between YBT measures (anterior, posteromedial, and posterolateral directions) and static balance measures: ellipse area (EA), length versus surface area (LVS), COP displacement anteroposterior (DAP) and mediolateral (DML), mean velocity anteroposterior (VAP) and mediolateral (VML), total mean velocity (TV). The magnitudes of the correlations were inferred on the basis of the following thresholds: 0.0-0.1, trivial; 0.1-0.3, small; 0.3-0.5, moderate; $0.5-0.7$, large; $0.7-0.9$, very large; $>0.9$, nearly perfect [42].
The significance of all statistical tests was set at $p$ $<0.05$. All statistical analyses were executed with the SPSS statistical analysis software (version 25.0, Chicago, USA).

\section{Ethical approval}

The research related to human use has complied with all the relevant national regulations and institutional policies, has followed the tenets of the Declaration of Helsinki, and has been approved by the local ethical committee of the Polytechnic Institute of Viana do Castelo, School of Sport and Leisure, with the code number IPVC-ESDL180801.

\section{Informed consent}

Informed consent has been obtained from all individuals included in this study.

\section{Results}

The baseline anthropometric characteristics of the participants are presented in Table 1.

Males were taller than females and had a greater body weight and lower body fat percentage $(p<0.05)$.

The descriptive statistics of the static balance test and differences between the sexes are presented in Table 2.

Males were significantly different $(p<0.05)$ than females in terms of static balance measures for all conditions (EOFS, ECFS, and CVVS). Females presented

Table 1. Baseline anthropometric characteristics of the studied population (mean $\pm S D$ )

\begin{tabular}{lllcc}
\hline Category & Age (years) & Height $(\mathrm{cm})$ & Body weight $(\mathrm{kg})$ & Body fat $(\%)$ \\
\hline Total $(n=77)$ & $19.1 \pm 1.1$ & $170.2 \pm 9.2$ & $64.1 \pm 10.7$ & $15.1 \pm 5.6$ \\
Males $(n=48)$ & $19.1 \pm 1.1$ & $175.2 \pm 7.1^{*}$ & $68.5 \pm 10.4^{*}$ & $13.1 \pm 5.1^{*}$ \\
Females $(n=29)$ & $19.0 \pm 1.1$ & $162.0 \pm 5.9$ & $56.9 \pm 6.4$ & $18.4 \pm 4.9$ \\
\hline
\end{tabular}

* significant differences between sexes $(\mathrm{p}<0.05)$ 


\section{HUMAN MOVEMENT}

C. Gonçalves et al., Relationship between static and dynamic balance

Table 2. Descriptive statistics (mean $\pm S D$ ) of static balance test for the overall population and by sex

\begin{tabular}{|c|c|c|c|c|c|c|c|}
\hline Category & $\begin{array}{c}\text { EA } \\
\left(\mathrm{cm}^{2}\right)\end{array}$ & $\begin{array}{c}\text { LVS } \\
\left(\mathrm{cm} / \mathrm{cm}^{2}\right)\end{array}$ & $\begin{array}{l}\text { DAP } \\
(\mathrm{cm})\end{array}$ & $\begin{array}{l}\text { DML } \\
(\mathrm{cm})\end{array}$ & $\begin{array}{l}\text { VAP } \\
(\mathrm{cm} / \mathrm{s})\end{array}$ & $\begin{array}{l}\text { VML } \\
(\mathrm{cm} / \mathrm{s})\end{array}$ & $\begin{array}{c}\mathrm{TV} \\
(\mathrm{cm} / \mathrm{s})\end{array}$ \\
\hline \multicolumn{8}{|l|}{ EOFS } \\
\hline $\begin{array}{l}\text { Total } \\
(n=77)\end{array}$ & $4.12 \pm 1.82$ & $14.92 \pm 5.40$ & $25.37 \pm 6.25$ & $40.74 \pm 9.39$ & $0.84 \pm 0.21$ & $1.36 \pm 0.31$ & $1.69 \pm 0.30$ \\
\hline $\begin{array}{l}\text { Males } \\
(n=48)\end{array}$ & $4.15 \pm 1.44$ & $14.99 \pm 4.82$ & $27.22 \pm 6.56^{*}$ & $43.24 \pm 9.29^{*}$ & $0.91 \pm 0.22^{*}$ & $1.44 \pm 0.31^{*}$ & $1.79 \pm 0.29 *$ \\
\hline $\begin{array}{l}\text { Females } \\
(n=29)\end{array}$ & $4.06 \pm 2.42$ & $14.78 \pm 6.45$ & $21.81 \pm 3.60$ & $35.96 \pm 7.68$ & $0.70 \pm 0.12$ & $1.19 \pm 0.26$ & $1.50 \pm 0.21$ \\
\hline \multicolumn{8}{|l|}{ ECFS } \\
\hline $\begin{array}{l}\text { Total } \\
(n=77)\end{array}$ & $5.24 \pm 2.27$ & $14.26 \pm 5.72$ & $30.99 \pm 9.96$ & $57.13 \pm 16.82$ & $1.05 \pm 0.35$ & $1.90 \pm 0.56$ & $2.38 \pm 0.70$ \\
\hline $\begin{array}{l}\text { Males } \\
(n=48)\end{array}$ & $5.63 \pm 2.31$ & $13.88 \pm 5.51$ & $33.51 \pm 10.54 *$ & $62.76 \pm 17.00 *$ & $1.14 \pm 0.37^{*}$ & $2.09 \pm 0.57^{*}$ & $2.61 \pm 0.71^{*}$ \\
\hline $\begin{array}{l}\text { Females } \\
(n=29)\end{array}$ & $4.58 \pm 2.07$ & $14.91 \pm 6.14$ & $26.69 \pm 7.23$ & $47.53 \pm 11.49$ & $0.89 \pm 0.24$ & $1.58 \pm 0.38$ & $1.98 \pm 0.43$ \\
\hline \multicolumn{8}{|l|}{ CVVS } \\
\hline $\begin{array}{l}\text { Total } \\
(n=77)\end{array}$ & $4.19 \pm 1.69$ & $13.66 \pm 4.68$ & $24.82 \pm 6.36$ & $41.24 \pm 9.70$ & $0.83 \pm 0.22$ & $1.37 \pm 0.32$ & $1.75 \pm 0.40$ \\
\hline $\begin{array}{l}\text { Males } \\
(n=48)\end{array}$ & $4.55 \pm 1.70^{*}$ & $13.69 \pm 4.82$ & $26.14 \pm 5.25^{*}$ & $43.87 \pm 8.94^{*}$ & $0.88 \pm 0.18^{*}$ & $1.46 \pm 0.30^{*}$ & $1.86 \pm 0.35^{*}$ \\
\hline $\begin{array}{l}\text { Females } \\
(n=29)\end{array}$ & $3.57 \pm 1.51$ & $13.60 \pm 4.52$ & $22.57 \pm 7.48$ & $36.79 \pm 9.47$ & $0.75 \pm 0.27$ & $1.22 \pm 0.32$ & $1.58 \pm 0.43$ \\
\hline
\end{tabular}

FS - foam surface, EO - eyes open, EC - eyes closed, CVVS - challenging the visual-vestibular system,

EA - ellipse area (sway area), LVS - length versus surface area, DAP - centre of pressure displacement anteroposterior, DML - centre of pressure displacement mediolateral, VAP - mean velocity anteroposterior, VML - mean velocity mediolateral, TV - total mean velocity

* significant differences between sexes $(p<0.05)$

Table 3. Descriptive statistics (mean $\pm S D$ ) of the Y Balance Test for the overall population and by sex

\begin{tabular}{lccc}
\hline Category & A $(\mathrm{cm})$ & PM $(\mathrm{cm})$ & PL $(\mathrm{cm})$ \\
\hline Total $(n=77)$ & $54.70 \pm 4.97$ & $72.61 \pm 7.21$ & $70.02 \pm 6.25$ \\
Males $(n=48)$ & $54.25 \pm 4.99$ & $73.75 \pm 7.28$ & $71.54 \pm 5.83^{*}$ \\
Females $(n=29)$ & $55.44 \pm 4.93$ & $70.73 \pm 6.81$ & $67.49 \pm 6.20$ \\
\hline
\end{tabular}

A - anterior direction, PM - posteromedial direction, PL - posterolateral direction

* significant differences between sexes $(p<0.05)$

a better stability index compared with males. Specifically, in EOFS, females improved 25\% DAP ( $p=0.01$, $d=0.96), 20 \%$ DML $(p<0.01, d=0.83), 30 \% \mathrm{VAP}$ $(p<0.01, d=1.11), 21 \%$ VML $(p<0.01, d=0.86)$, $19 \%$ TV $(p<0.01, d=1.10)$ as compared with males. In ECFS, the improvements were $26 \%$ DAP $(p<0.01$, $d=0.72), 32 \%$ DML $(p<0.01, d=1.00), 28 \%$ VAP $(p<0.01, d=0.76), 32 \% \mathrm{VML}(p<0.01, d=1.01)$, and $32 \%$ TV $(p<0.01, d=1.02)$. In CVVS, they equalled $27 \% \operatorname{EA}(p=0.02, d=0.60), 26 \% \operatorname{DAP}(p=0.02, d=$ $0.58), 19 \%$ DML $(p<0.01, d=0.77), 17 \% \operatorname{VAP}(p=0.02$, $d=0.60), 20 \% \mathrm{VML}(p<0.01, d=0.78)$, and $18 \% \mathrm{TV}$ $(p=0.01, d=0.73)$.
The descriptive statistics of the dynamic balance test are presented in Table 3.

Males were significantly different $(p<0.05)$ than females in terms of YBT test results only for the posterolateral direction (Table 3). Males presented 6\% better performance in YBT posterolateral than females ( $p=0.01, d=0.68)$.

The magnitudes of correlations between YBT measures and static balance measures under different unstable conditions were also assessed, first for the participants overall and then by sex (Figure 2).

No large correlations were found between YBT and static balance measures for the EOFS condition 

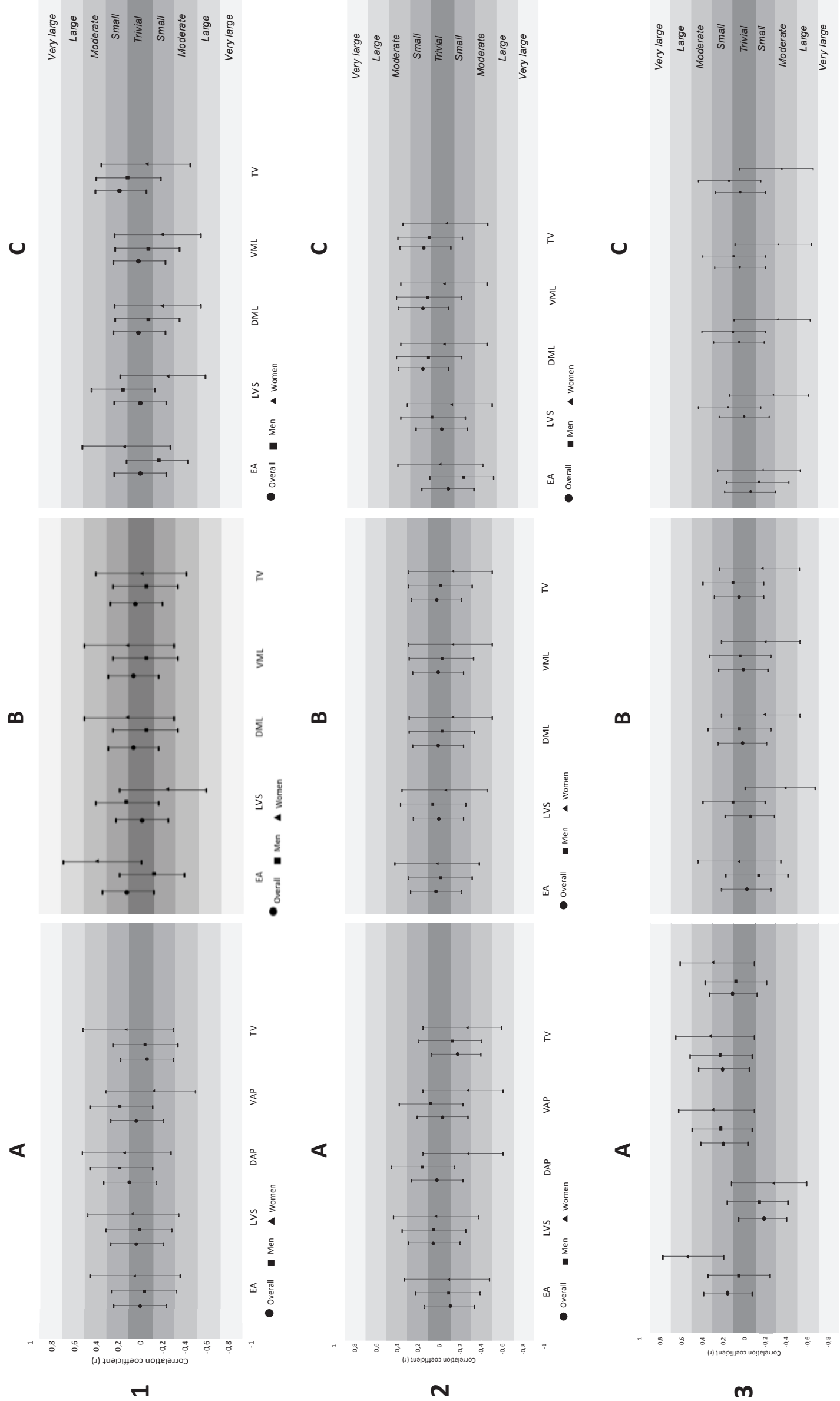

$\infty$
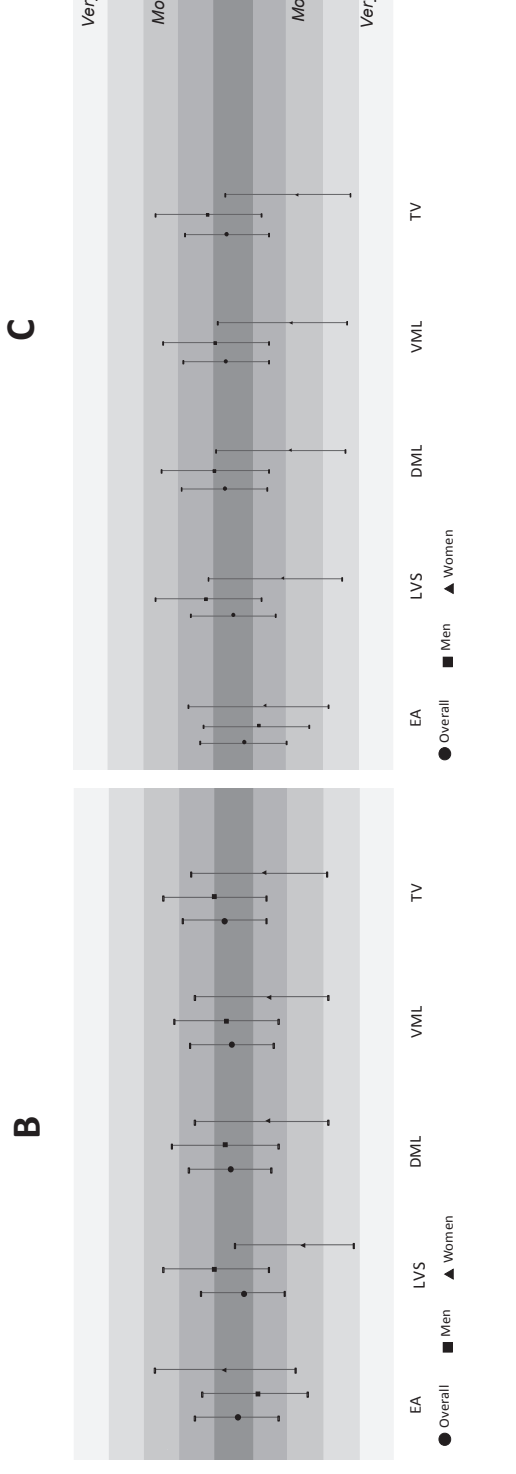

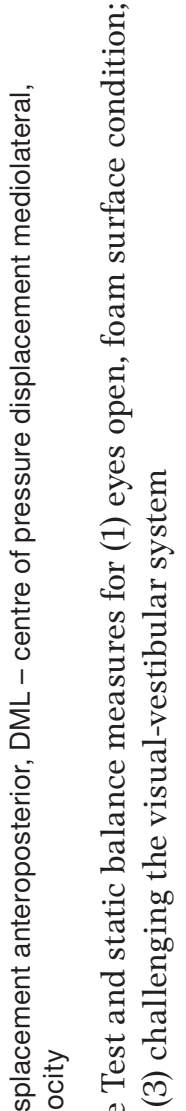

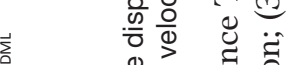

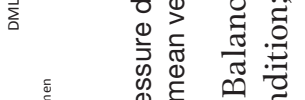

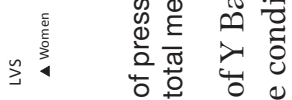

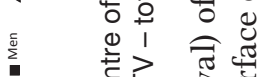

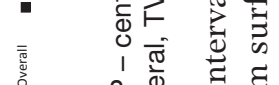

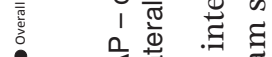

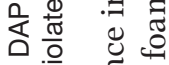
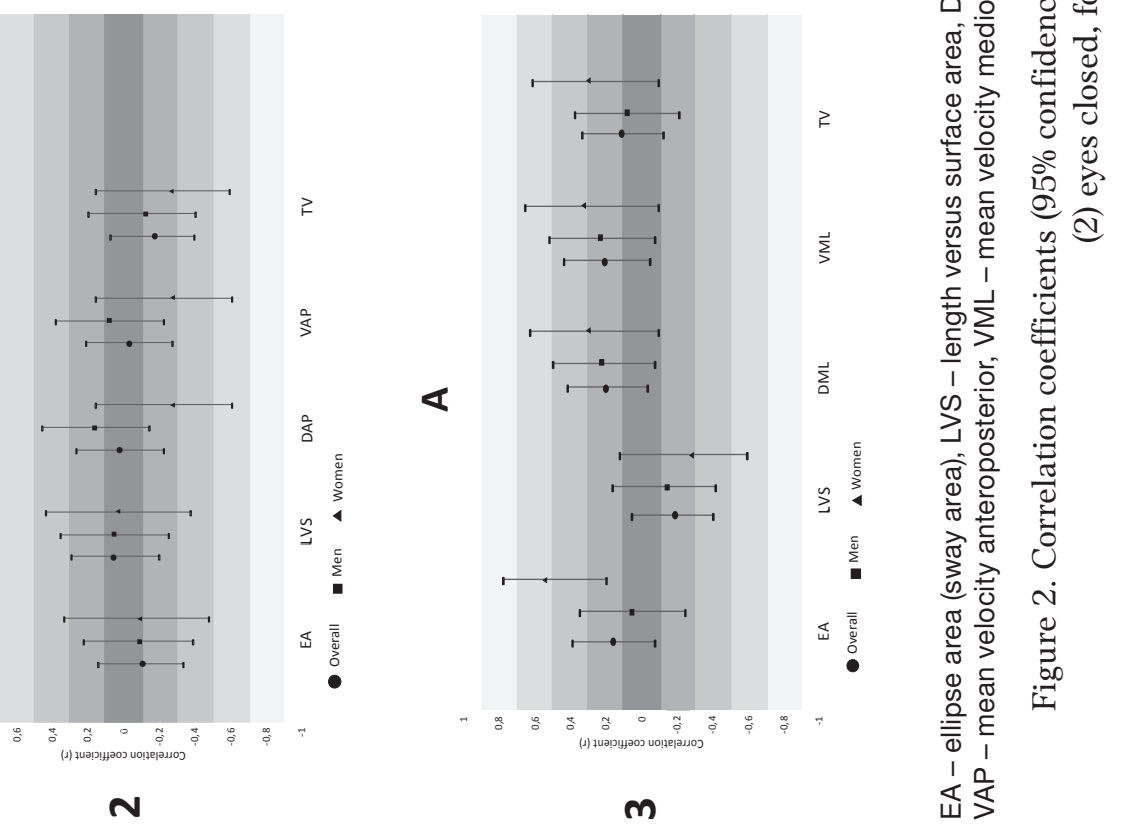

品敢

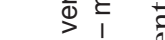

产岕

胥

1.

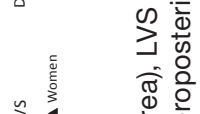

气

-

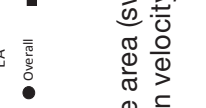

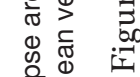

를

㟧是 
(Figure 2-1) or the ECFS condition (Figure 2-2). Large positive correlations were observed between YBT anterior direction and EA in women $[r=0.54(0.19 ; 0.77)]$ for the CVVS condition (Figure 2-3A).

\section{Discussion}

This study aimed to compare the static and dynamic balance of men and women and to analyse the relationship between static and dynamic balance measures. Females presented better stability indices than males under all conditions, and small to moderate correlations were found between static and dynamic balance.

Despite the inconsistency of previously reported results, most recent studies have shown that men and women differ in terms of balance. Females seem to have better static balance control than males in anteroposterior and mediolateral stability indices [31-33, 43]. Our data are consistent with previous literature, as female participants presented lower COP displacement and velocity $\mathrm{COP}$ displacement values than men in all conditions (EOFS, ECFS, and CVVS), which reflects a better stability index. This observation could be due to anthropometric factors (postural balance seems more influenced by anthropometric factors in men) [43], neuromuscular factors (flexibility/mobility), neurophysiologic factors (processing of inferences); a reason may also be that women often wear high heels, which constantly challenges their balance [32].

However, our observations were different for dynamic balance control. Specifically, YBT assessment revealed that males performed better than females but only in the posterolateral reach direction. This is not consistent with the findings by Ericksen and Gribble [44], who showed that women demonstrated greater reach distances for anterior, medial, and posterior reaches in SEBT. The difference between the 2 studies can perhaps be explained by the fact that Ericksen and Gribble [44] utilized medial and posterior reaches in SEBT, whereas the present study considered the posteromedial and posterolateral reach directions. To the best of our knowledge, no authors have previously compared the reaches of young adult men and women in the anterior, posteromedial, and posterolateral directions.

Previous literature reports a relationship between static and dynamic balance [27-29, 45]. For example, Karimi and Solomonidis [27] concluded that there was no significant correlation between static and dynamic stability parameters. This is because static balance tests assess the stability of participants while in a quiet standing position; meanwhile, dynamic balance tests are more specific and challenging than static tests. The authors suggest that static test performance does not reflect balance task performance [27].

Additionally, Sell [28] examined the relationship and differences between static and dynamic postural stability in healthy, physically active adults. A lack of correlation between static and dynamic balance was found, and the dynamic postural stability scores were significantly higher than static postural stability scores. Dynamic balance tests seem to be more challenging than static balance tests, which could explain the weak relationship between the 2 types of tests [28].

Furthermore, Kim et al. [29] verified the differences between the static and dynamic stability of participants with flexible flatfeet and neutral feet. No relationship was observed between COP speed and YBT scores in either group. In another work, Pau et al. [45] analysed young adults and professional elite soccer players and arrived at the same conclusions (i.e., there was no significant correlation between static and dynamic balance parameters).

Generally, our data show small to moderate correlations between static and dynamic postural balance test performance, which is consistent with most previous research involving active young adults [27, 28] and young athletes [45]. The present results suggest that static balance assessments involving a force plate (with an unstable surface and challenging the visualvestibular system) seem to differ from YBT assessments of cognitive and motor skills. This difference might be because static and dynamic balance are regulated by different mechanisms [27-29, 45]. In fact, although YBT has been considered a reliable instrument for assessing dynamic balance, some studies have reported that this test requires strength, proprioception, and joint mobility in addition to balance [39].

Another possible reason for the present result is related to the different requirements concerning muscle strength and muscular activation to perform static and dynamic tests. It seems that to maintain body control during YBT (which involves anterior, posteromedial, and posterolateral maximal reaches), participants need neuromuscular control, which is gained through proper joint positioning and proper strength in the principal musculature [23, 46]. Additionally, during a static postural control task, the objective is to minimize COP displacement, which is derivative of the vertical ground reaction force [23, 46]. Meanwhile, the goal of YBT is to assess dynamic postural control by 
forcing participants to disturb their balance as they try to reach maximum distances while maintaining unilateral support [23, 46].

YBT movement patterns differ from the movements carried out during everyday activities [46], as people do not commonly challenge their balance to the joint range of motion required during YBT. In fact, these static and dynamic tests seem to be different, as they require different skills. YBT is considered a dynamic balance test that demands specific skills that differ from those inherent in the static balance test.

The present data also showed a large and positive correlation between the YBT anterior direction and sway area for the CVVS condition in females. No other significant correlations were found between static and dynamic balance in males or females. This observation suggests that females with higher performance in YBT anterior (i.e., females with better dynamic balance) tend to present higher values in the sway area (i.e., they have weaker static balance) when instructed to move their head to challenge their visual-vestibular system.

The lack of previous evidence from studies with a similar objective makes it difficult to provide a general discussion of the results.

\section{Limitations of the study and future directions}

There are several limitations in the present study. The sample was composed of active young adults with different sports experiences. Therefore, before the static and dynamic balance assessment, it would be important to characterize the type, frequency, and intensity of the sports activity, as well as divide the participants in accordance with these factors.

The study investigated the relationship between static and dynamic balance. For the static balance assessment, the subjects performed the test with bipedal support, and for YBT, they were forced to use unipedal support. This may bias the results and discussion as the lower-extremity, trunk, and core muscular activation and joint stability/mobility during each YBT direction reach was not controlled. It should be interesting to investigate the differences between YBT measures in muscular activation and joint stability/ mobility in the same sample (young adults undertaking sports activity). Also, it will be noteworthy to verify the influence of mobility program training on the YBT performance, and the influence or contributions of the proximal and distal joints range of motion.

\section{Practical applications and study relevance implications}

- The balance and postural control assessment can help to understand why balance disorders occur and how to prevent injuries.

- The small to moderate correlations between static and dynamic measures of balance and postural control indicate that people present different responses when attempting to maintain postural balance stability. Static and dynamic balance appear to be independent of each other; thus, they might need to be tested and trained complementarily. Dynamic balance tests seem to be more specific and challenging than static tests, particularly for young adults.

- Static and dynamic balance measures are useful for assessing both balance and postural control. However, we suggest that tests should be carefully chosen to ensure that they are appropriate for the study population of interest.

\section{Conclusions}

This study reveals small to moderate correlations between static and dynamic measures of balance and postural control, suggesting a weak relationship between static and dynamic balance test performance.

However, the positive correlation between YBT and sway area implies that females with high YBT anterior performance (i.e., good dynamic balance) tend to present a greater sway area (i.e., poor static balance) when instructed to move their head and challenge their visual-vestibular system.

\section{Acknowledgements}

The authors would like to thank the study participants and the research staff who contributed to the study. The authors would also like to acknowledge the Escola Superior de Desporto e Lazer de Melgaço for all equipment and training space provided. The study received no financial or technical support, did not constitute an independent project of external funding or corporate sponsorship.

\section{Disclosure statement}

No author has any financial interest or received any financial benefit from this research.

\section{Conflict of interest}

The authors state no conflict of interest. 


\section{References}

1. Horak FB. Postural orientation and equilibrium: what do we need to know about neural control of balance to prevent falls? Age Ageing. 2006;35(Suppl. 2):ii7-ii11; doi: 10.1093/ageing/afl077.

2. Winter DA, Patla AE, Frank JS. Assessment of balance control in humans. Med Prog Technol. 1990; 16(1-2):31-51.

3. Clark MA, Lucett SC, Sutton BG. NASM essentials of personal fitness training. Baltimore: Lippincott Williams \& Wilkins; 2012.

4. Duarte M, Freitas SMSF. Revision of posturography based on force plate for balance evaluation [in Portuguese]. Rev Bras Fisioter. 2010;14(3):183-192; doi: 10.1590/S1413-35552010000300003.

5. Kurz A, Lauber B, Franke S, Leukel C. Balance training reduces postural sway and improves sport-specific performance in visually impaired cross-country skiers. J Strength Cond Res. 2021;35(1):247-252; doi: 10.1519/ JSC.0000000000002597.

6. Sell TC, Tsai Y-S, Smoliga JM, Myers JB, Lephart SM. Strength, flexibility, and balance characteristics of highly proficient golfers. J Strength Cond Res. 2007; 21(4):1166-1171; doi: 10.1519/R-21826.1.

7. Artioli DP, Bryk FF, Fukuda T, de Almeida Carvalho NA. Neuromuscular control test in individuals submitted anterior cruciate ligament reconstruction and in advanced physiotherapeutic treatment [in Portuguese]. Rev Bras Clin Med. 2011;9(4):269-273.

8. Cerrah A, Bayram İ, Yıldızer G, Uğurlu O, Şimşek D, Ertan H. Effects of functional balance training on static and dynamic balance performance of adolescent soccer players. Int J Sports Exerc Train Sci. 2016;2(2):7381; doi: 10.18826/ijsets.3889.

9. Lizardo F, Ronzani G, Sousa L, S O, Santos L, Lopes P, et al. Proprioceptive exercise with BOSU maximizes electromyographic activity of the ankle muscles. Biosci J. 2017;33(3):754-762; doi: 10.14393/BJ-v33n3-32840.

10. Namin SV, Letafatkar A, Farhan V. Effects of balance training on movement control, balance and performance in females with chronic ankle instability. Hormozgan Med J. 2017;21(3):188-199; doi: 10.29252/hmj.21.3.188.

11. Anderson K, Behm DG. The impact of instability resistance training on balance and stability. Sports Med. 2005;35(1):43-53; doi: 10.2165/00007256-20053501000004.

12. Janura M, Bizovska L, Svoboda Z, Cerny M, Zemkova E. Assessment of postural stability in stable and unstable conditions. Acta Bioeng Biomech. 2017;19(4):89-94; doi: 10.5277/ABB-00832-2017-02.

13. Cruz A, de Oliveira EM, Lopes Melo SI. Biomechanical analysis of equilibrium in the elderly. Acta Ortop Bras. 2010;18(2):96-99; doi: 10.1590/S1413-7852201 0000200007.

14. Opala-Berdzik A, Bacik B, Cieślińska-Świder J, Plewa M, Gajewska M. The influence of pregnancy on the location of the center of gravity in standing position. $\mathrm{J}$
Hum Kinet. 2010;26:5-11; doi: 10.2478/v10078-0100042-1.

15. Alves Alcantara CP, Manzieri Prado J, Duarte M. Analysis of the balance control in surfers during the erect posture [in Portuguese]. Rev Bras Med Esporte. 2012;18(5): 318-321; doi: 10.1590/S1517-86922012000500007.

16. Valovich McLeod TC, Armstrong T, Miller M, Sauers JL. Balance improvements in female high school basketball players after a 6-week neuromuscular-training program. J Sport Rehabil. 2009;18(4):465-481; doi: 10.1123/jsr.18.4.465.

17. Zech A, Klahn P, Hoeft J, zu Eulenburg C, Steib S. Time course and dimensions of postural control changes following neuromuscular training in youth field hockey athletes. Eur J Appl Physiol. 2014;114(2):395-403; doi: 10.1007/s00421-013-2786-5.

18. Curtolo M, Tucci HT, Souza TP, Gonçalves GA, Lucato AC, Yi LC. Balance and postural control in basketball players. Fisioter Mov. 2017;30(2):319-328; doi: 10.1590/1980-5918.030.002.AO12.

19. Benis R, Bonato M, La Torre AL. Elite female basketball players' body-weight neuromuscular training and performance on the Y-Balance Test. J Athl Train. 2016; 51(9):688-695; doi: 10.4085/1062-6050-51.12.03.

20. Coughlan GF, Fullam K, Delahunt E, Gissane C, Caulfield BM. A comparison between performance on selected directions of the Star Excursion Balance Test and the Y Balance Test. J Athl Train. 2012;47(4):366-371; doi: 10.4085/1062-6050-47.4.03.

21. Cuğ M, Duncan A, Wikstrom E. Comparative effects of different balance-training-progression styles on postural control and ankle force production: a randomized controlled trial. J Athl Train. 2016;51(2):101-110; doi: 10.4085/1062-6050-51.2.08.

22. Sabau E, Niculescu G, Popescu F, Porfirescu C, Gevat C, Lupu E. Study of dynamic postural control in young adults. Sci Mov Health. 2015;15(2, Suppl.):515-520.

23. Gribble PA, Hertel J. Considerations for normalizing measures of the Star Excursion Balance Test. Meas Phys Educ Exerc Sci. 2003;7(2):89-100; doi: 10.1207/S15 327841MPEE0702_3.

24. Lions C, Bucci MP, Bonnet C. Postural control can be well maintained by healthy, young adults in difficult visual task, even in sway-referenced dynamic conditions. PLoS One. 2016;11(10):e0164400; doi: 10.1371/ journal.pone.0164400.

25. Oba N, Sasagawa S, Yamamoto A, Nakazawa K. Difference in postural control during quiet standing between young children and adults: assessment with center ofmass acceleration.PLoSOne.2015;10(10):e0140235; doi: 10.1371/journal.pone.0140235.

26. Hrysomallis C, McLaughlin P, Goodman C. Relationship between static and dynamic balance tests among elite Australian footballers. J Sci Med Sport. 2006;9(4): 288-291; doi: 10.1016/j.jsams.2006.05.021.

27. Karimi MT, Solomonidis S. The relationship between parameters of static and dynamic stability tests. J Res Med Sci. 2011;16(4):530-535. 
28. Sell TC. An examination, correlation, and comparison of static and dynamic measures of postural stability in healthy, physically active adults. Phys Ther Sport. 2012; 13(2):80-86; doi: 10.1016/j.ptsp.2011.06.006.

29. Kim J-A, Lim O-B, Yi C-H. Difference in static and dynamic stability between flexible flatfeet and neutral feet. Gait Posture. 2015;41(2):546-550; doi: 10.1016/j. gaitpost.2014.12.012.

30. Brachman A, Kamieniarz A, Michalska J, Pawłowski M, Słomka KJ, Juras G. Balance training programs in athletes - a systematic review. J Hum Kinet. 2017; 58(1):45-64; doi: 10.1515/hukin-2017-0088.

31. Alves CM, Santana EM, Naves ELM. Influence of visual and proprioceptive systems in the postural balance of young adults. In: Costa-Felix R, Machado J, Alvarenga A (eds.), XXVI Brazilian Congress on Biomedical Engineering. Singapore: Springer; 2019; 277-282.

32. D’Andréa Greve JM, Cuğ M, Dülgeroğlu D, Brech GC, Castilho Alonso A. Relationship between anthropometric factors, gender, and balance under unstable conditions in young adults. Biomed Res Int. 2013;2013: 850424; doi: 10.1155/2013/850424.

33. Masui T, Hasegawa Y, Matsuyama Y, Sakano S, Kawasaki M, Suzuki S. Gender differences in platform measures of balance in rural community-dwelling elders. Arch Gerontol Geriatr. 2005;41(2):201-209; doi: 10.1016/j.archger.2005.02.003.

34. Panzer VP, Bandinelli S, Hallett M. Biomechanical assessment of quiet standing and changes associated with aging. Arch Phys Med Rehabil. 1995;76(2):151-157; doi: 10.1016/s0003-9993(95)80024-7.

35. Yoshida K, Iwakura H, Inoue F. Motion analysis in the movements of standing up from and sitting down on a chair. A comparison of normal and hemiparetic subjects and the differences of sex and age among the normals. Scand J Rehabil Med. 1983;15(3):133-140.

36. Silva Pirôpo U, dos Santos Rocha JA, da Silva Passos R, Lomanto Couto D, dos Santos AM, Barbosa Argolo AM, et al. Influence of visual information in postural control: impact of the used stabilometric analysis methods. Eur J Hum Mov. 2016;37:21-29.

37. Munro AG, Herrington LC. Between-session reliability of the Star Excursion Balance Test. Phys Ther Sport. 2010;11(4):128-132; doi: 10.1016/j.ptsp.2010.07.002.

38. Anthony CC, Brown LE, Coburn JW, Galpin AJ, Tran TT. Stance affects balance in surfers. Int J Sports Sci Coach. 2016;11(3):446-450; doi: 10.1177/174795411 6645208.

39. Plisky PJ, Gorman PP, Butler RJ, Kiesel KB, Underwood FB, Elkins B. The reliability of an instrumented device for measuring components of the Star Excursion Balance Test. N Am J Sports Phys Ther. 2009;4(2):92-99.

40. Paillard T, Lafont C, Costes-Salon MC, Rivière D, Dupui P. Effects of brisk walking on static and dynamic balance, locomotion, body composition, and aerobic capacity in ageing healthy active men. Int J Sports Med. 2004;25(7):539-546; doi: 10.1055/s-2004-820948.
41. Gribble PA, Kelly SE, Refshauge KM, Hiller CE. Interrater reliability of the Star Excursion Balance Test. J Athl Train. 2013;48(5):621-626; doi: 10.4085/10626050-48.3.03.

42. Hopkins WG, Marshall SW, Batterham AM, Hanin J. Progressive statistics for studies in sports medicine and exercise science. Med Sci Sports Exerc. 2009;41(1):313; doi: 10.1249/MSS.0b013e31818cb278.

43. Castilho Alonso A, Luna NMS, Mochizuki L, Barbieri F, Santos S, D’Andréa Greve JM. The influence of anthropometric factors on postural balance: the relationship between body composition and posturographic measurements in young adults. Clinics. 2012;67(12):14331441; doi: 10.6061/clinics/2012(12)14.

44. Ericksen H, Gribble PA. Sex differences, hormone fluctuations, ankle stability, and dynamic postural control. J Athl Train. 2012;47(2):143-148; doi: 10.4085/10626050-47.2.143.

45. Pau M, Arippa F, Leban B, Corona F, Ibba G, Todde F, et al. Relationship between static and dynamic balance abilities in Italian professional and youth league soccer players. Phys Ther Sport. 2015;16(3):236-241; doi: 10.1016/j.ptsp.2014.12.003.

46. Kinzey SJ, Armstrong CW. The reliability of the starexcursion test in assessing dynamic balance. J Orthop Sports Phys Ther. 1998;27(5):356-360; doi: 10.2519/ jospt.1998.27.5.356. 